\title{
Mapping Global Industrial Value Added
}

\author{
Wei Song, Huiyi Zhu, Han Li, Qian Xue, and Yuanzhe Liu
}

\section{Background}

In the research of identifying the impact of climate change on the industrial economic system, the core step is to overlay climate data and industrial economic data with the same spatiotemporal resolution and perform spatial analysis (Zhao et al. 2017). However, the risk assessment of the industrial economic system is hampered by the lack of spatialized datasets of global and Chinese industrial economic system output value, especially under future climate scenarios, because it is difficult to accurately identify the output value of secondary and tertiary industries by conventional remote sensing methods. The existing spatial data of industrial economic system output value are mostly at the provincial, city, and county levels, with administrative areas as the smallest spatial units, which cannot represent the difference and spatial distribution of industrial output value within a province or a city. Therefore, it is difficult to carry out overlay analysis with gridded climate data in risk assessment. Although there are some spatialized data on the output value of a particular industry from research (Dong et al.

Authors: Wei Song, Huiyi Zhu, Han Li, Qian Xue, Yuanzhe Liu. Map Designers: Yuanyuan Jing, Jing'ai Wang, Ying Wang. Language Editor: Song Wei.

W. Song $(\bowtie) \cdot$ H. Zhu $\cdot$ H. Li $\cdot$ Q. Xue $\cdot$ Y. Liu

Key Laboratory of Land Surface Pattern and Simulation, Institute of Geographic Sciences and Natural Resources Research, Chinese Academy of Sciences, Beijing, 100101, China

e-mail: songw@igsnrr.ac.cn

H. Li

University of Chinese Academy of Sciences, Beijing, 100049,

China

Q. Xue

Chongqing Jiaotong University, Chongqing, 400074, China

Y. Liu

Shandong Normal University, Jinan, 250358, China
2016), in general, there is a lack of large-scale, high-resolution, and comprehensive spatial data of industrial output value.

Currently, the research methods of mapping economic data can be divided into three categories: spatial interpolation model (Tobler 1979), multi-source data fusion model (Li et al. 2018), and remote sensing inverse model (Wang et al. 2018). Compared with other spatial models, the nighttime light remote sensing data inversion model is characterized by simple implementation and high precision and is expected to solve the problem of large-scale data localization. However, the model is mainly used to analyze gross domestic product (GDP) and population data. Based on the existing applications, this study developed a method to spatialize the industrial output on a global scale, and the random forest algorithm in machine learning was used to map the industrial value added under different climate change scenarios in the future.

The definition of industrial value added is based on the World Bank's statistical standards. The industrial value added covers mining, manufacturing, construction, electricity, water, and gas sectors. Industrial value added statistics data are from the World Bank, and the data are in current U. S. dollars.

\section{Method}

The method for mapping industrial value added for future climate scenarios includes the following steps: (1) Mapping the current industrial value added; (2) Simulating the spatial boundary of future industrial value added; and (3) Estimating 
Fig. 1 Technical flowchart of mapping global industrial value added

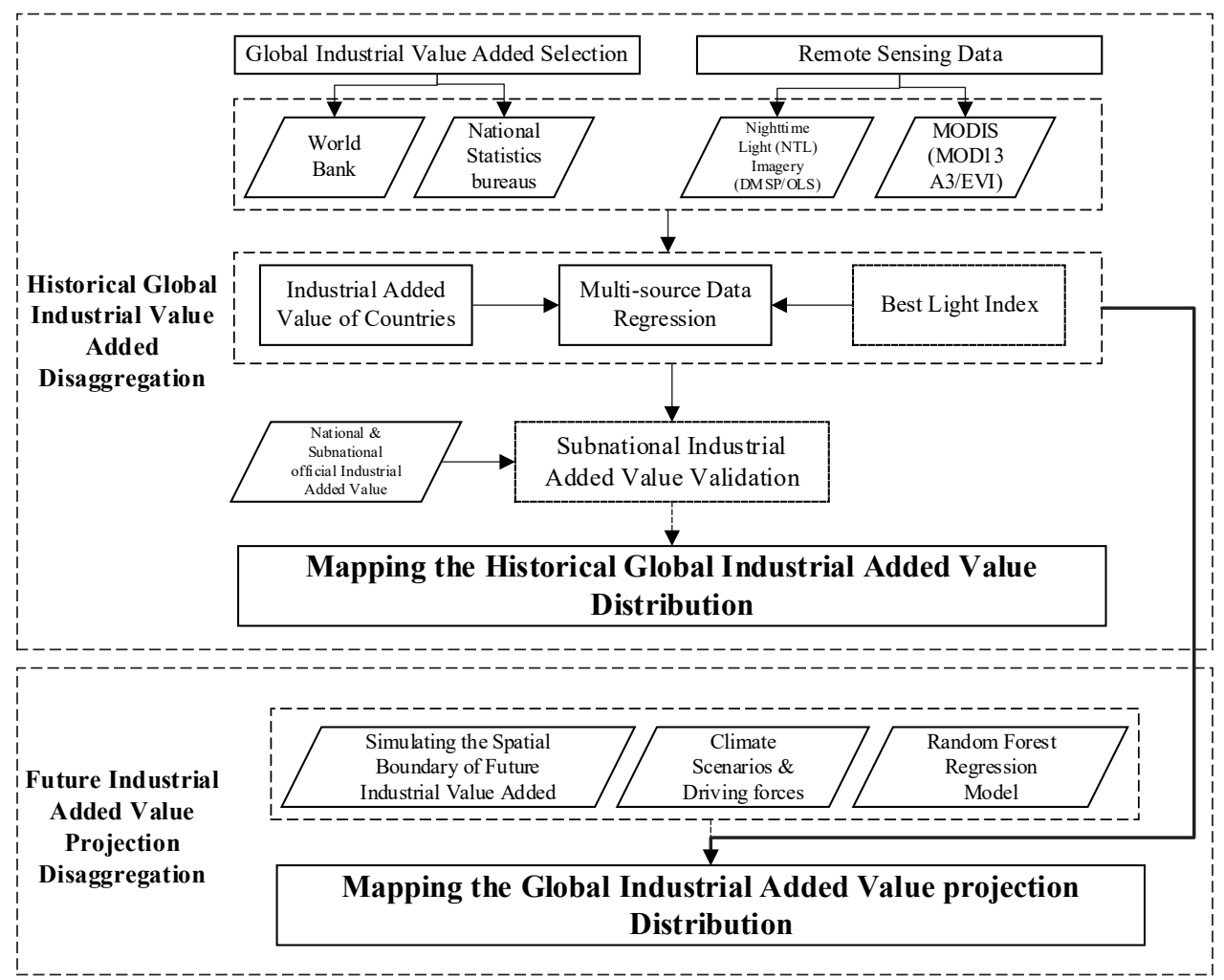

the future industrial value added. Figure 1 shows the technical flowchart for mapping industrial value added.

\subsection{Mapping the Current Industrial Value Added}

Based on the 2010 global vegetation index data (Enhanced Vegetation Index, EVI, from MODIS) and the 2010 nighttime light remote sensing data (from DMSP/OLS), the adjustment nighttime light index (ANLTI) was constructed to preprocess the light saturation and overflow phenomena of nighttime light data, and the best light data in the world was obtained. The calculation formula is as follows (Zhuo et al. 2015):

$$
\mathrm{ANLTI}=\frac{2}{1-\mathrm{NT}_{\mathrm{n}}+\mathrm{EVI}} \times \mathrm{NT}
$$

ANLTI is the EVI adjusted nighttime light index, $\mathrm{NT}_{\mathrm{n}}$ is the normalized nighttime light value, and NT is the original nighttime light value.

A regression model of the industrial value added was constructed using the adjusted nighttime light index (ANLTI) and industrial value added statistical data of countries from the World Bank. The data of global industrial value added in 2010 is generated using the following formula:

$$
I=\frac{I_{i} \times \mathrm{ANLTI}}{\mathrm{ANLTI}_{i}}
$$

$I$ is the industrial value added of each pixel. $I_{i}$ is the total industrial added value of the country in which the pixel is located, and $\mathrm{ANLTI}_{i}$ is the total EVI adjusted nighttime light index of the country in which the pixel is located.

In the global scope, statistical industrial value added in 178 provincial (state) regions were randomly selected for the correlation test, and the correlation coefficient is 0.93 . Taking statistical data as the true values, the average accuracy of industrial value added in the 178 regions is $80.14 \%$ (Xue

\subsection{Simulating the Spatial Boundary of Future Industrial Value Added}

Future industrial value added changes can be approximated by starting with industrial land use change. According to the principle of logistic-cellular automata (CA)-Markov simulation, the global land use data from ESA (European Space Agency, https://maps.elie.ucl.ac.be/CCI/viewer/index.php) in 2010 and 2015 were used to simulate the land use change in 2030 and 2050. The urban land was extracted as the spatial boundary of the future industrial added value. In the selection of driving factors, it is necessary to comprehensively describe the impact of different driving factors on land et al. 2018). 
use change, and consider the research scale. Elevation, slope, population, GDP, and distance from river and road are selected as driving factors of land use. The data are from NOAA (National Oceanic and Atmospheric Administration, https://www.noaa.gov/), SEDA (Socioeconomic Data and Applications Center, https://sedac.ciesin.columbia.edu/), Global Risk Data Platform (https://preview.grid.unep.ch/), and Natural Earth (https://www.naturalearthdata.com/). The accuracy of the simulated land use in 2015 is verified by using the global land use data in 2015. The global average accuracy is $91.89 \%$.

The logistic-CA-Markov model is mainly used in the simulation of land use change by combining the characteristics of the logistic regression model, the CA model, and the Markov model (Jamal et al. 2013). The logistic regression model can analyze the relationship between land use types and driving forces. The CA model can effectively simulate the spatial changes of the land use system and the Markov model can predict the quantitative changes of land use types so as to simulate land use changes more comprehensively and accurately.

\subsection{Estimating Future Industrial Value Added}

For the spatialization of industrial added value under different climate change scenarios in the future, appropriate factors of industrial added value change need to be selected. In order to determine the influencing factors of spatial change of industrial value added, land use, population density, and accessibility of the study area should be comprehensively considered. In addition, the distribution of rivers and lakes, and topographic features such as elevation and slope should be considered. Due to the many influencing factors, the ordinary regression model is difficult to comprehensively and accurately reflect the spatial distribution characteristics of the industrial added value under different climate change scenarios. Therefore, this study is based on machine learning, combined with the random forest model to build a spatial model of industrial added value under different climate change scenarios and the model is as follows (Xue and Song 2020):

$$
F=(T, P, \text { GDP }, \text { Land, Slope, Pop. . })
$$

where $F$ represents simulation results under different climate change scenarios, $T$ represents average annual temperature, $P$ represents average annual precipitation, GDP represents the gross domestic product, Land represents the spatial boundary of future industrial value added, and Pop represents the density of population.

The driving factors used to build the random forest model include industrial value added in 2010, the spatial distribution of urban land, elevation, slope, distance from rivers, distance from roads, distance from railroads, distance from residential settlements, and air temperature and precipitation (representing different climate change scenarios). When mapping the future industrial added value under different climate change scenarios, these driving factors are constant except for temperature and precipitation.

Based on the comprehensive consideration of the fitting speed and accuracy of the model, the parameters of the random forest model were tested. Finally, we built a total of 100 decision trees. In each decision tree, $90 \%$ of the samples were randomly selected to build the sample model, and the remaining $10 \%$ were used as test data. The simulation results show that the sample accuracy was 0.94 and the test sample accuracy was 0.81 . The overall sample accuracy was relatively high, which can well explain the influence of various factors on the industrial value added, so it can be used for the simulation and prediction of industrial added value.

Through the statistics of the proportion of industrial value added in GDP (from the World Bank) and the GDP data under the Shared Socioeconomic Pathways (SSPs), the industrial added value of each country under different SSP scenarios in the future was obtained. According to the estimated proportion of industrial value added of each country and the proportion of industrial value added of each country under different SSP scenarios in the future, the regression model was constructed. Finally, the distribution of industrial added value under SSP1, SSP2, and SSP3 scenarios in 2030 and 2050 was obtained.

\section{Results}

The industrial value added under different future climate change scenarios was calculated by continent. Then we derived the statistical value of industrial value added of each continent under SSP1, SSP2, and SSP3 scenarios in 2010, 2030, and 2050 (Fig. 2). Overall, in the future, the industrial value added will increase obviously. Compared with other regions, Asia has the largest industrial value added, followed by North America, Europe, Africa, and South America, and Oceania has the smallest industrial value added. The industrial value added of SSP1 was the biggest, followed by SSP2, and the smallest was SSP3. 


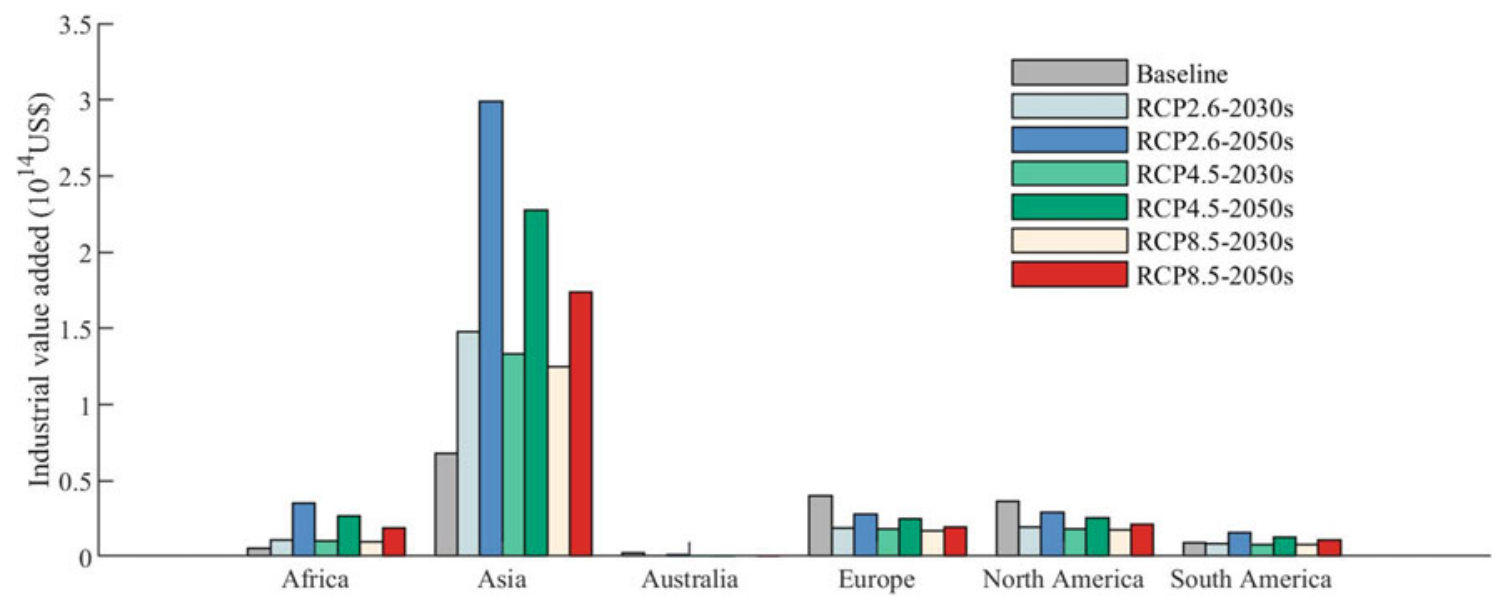

Fig. 2 Industrial value added under the Shared Socioeconomic Pathway (SSP) 1, SSP2, and SSP3 scenarios in 2030 and 2050 


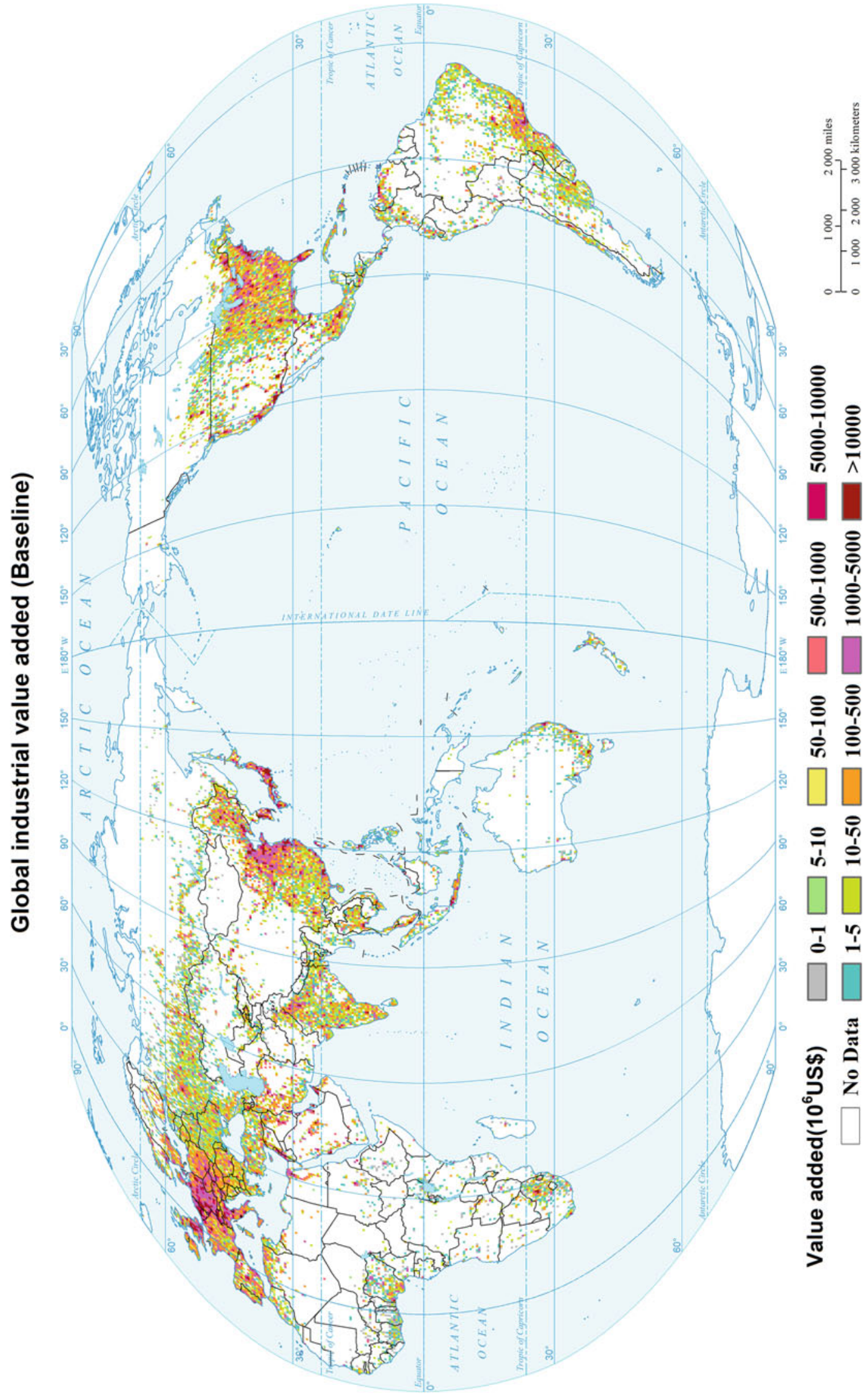




\section{Projected global industrial value added (2030, SSP1)}

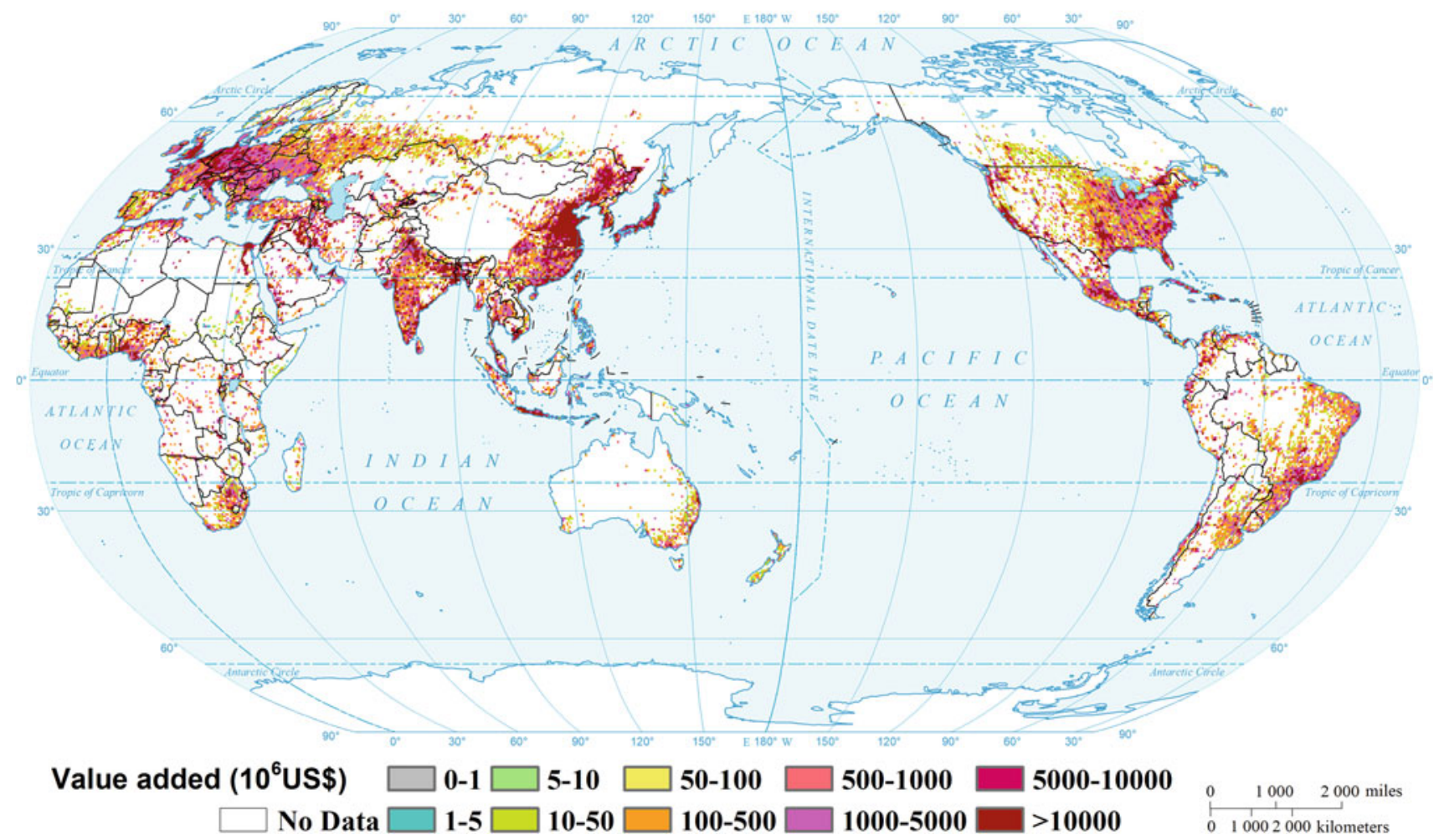

Projected global industrial value added (2030, SSP2)

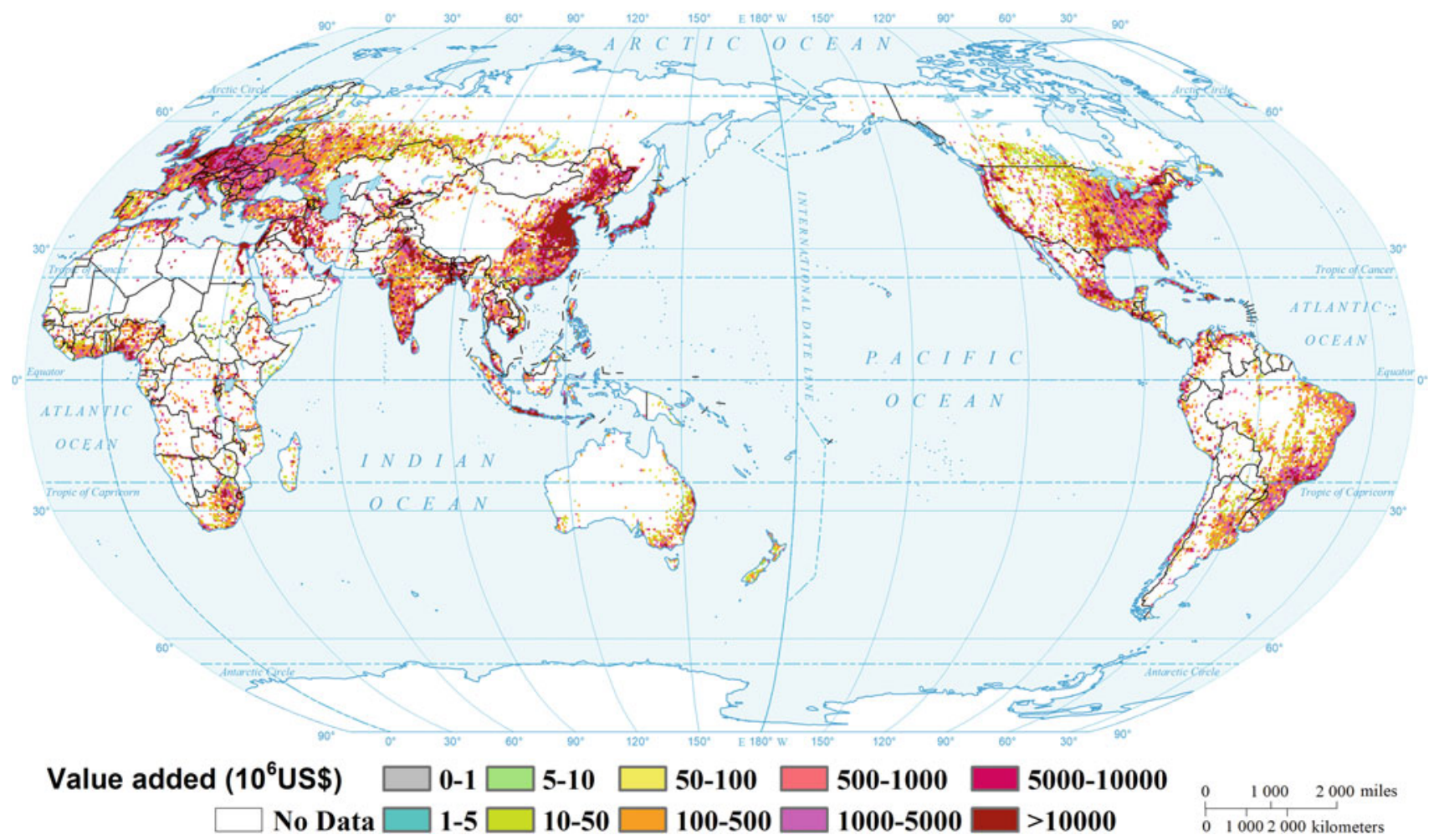




\section{Projected global industrial value added (2030, SSP3)}

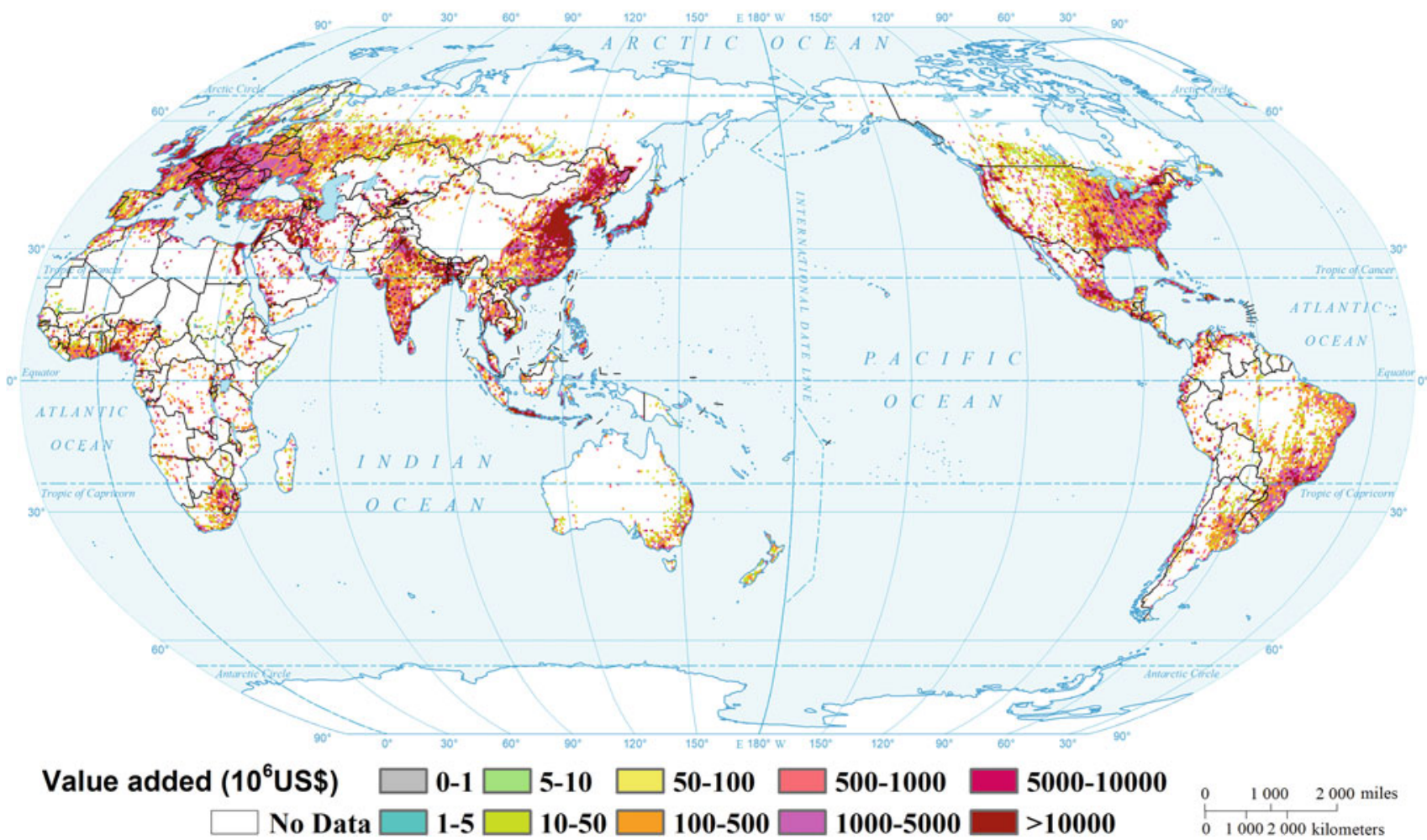

\section{Projected global industrial value added (2050, SSP1)}

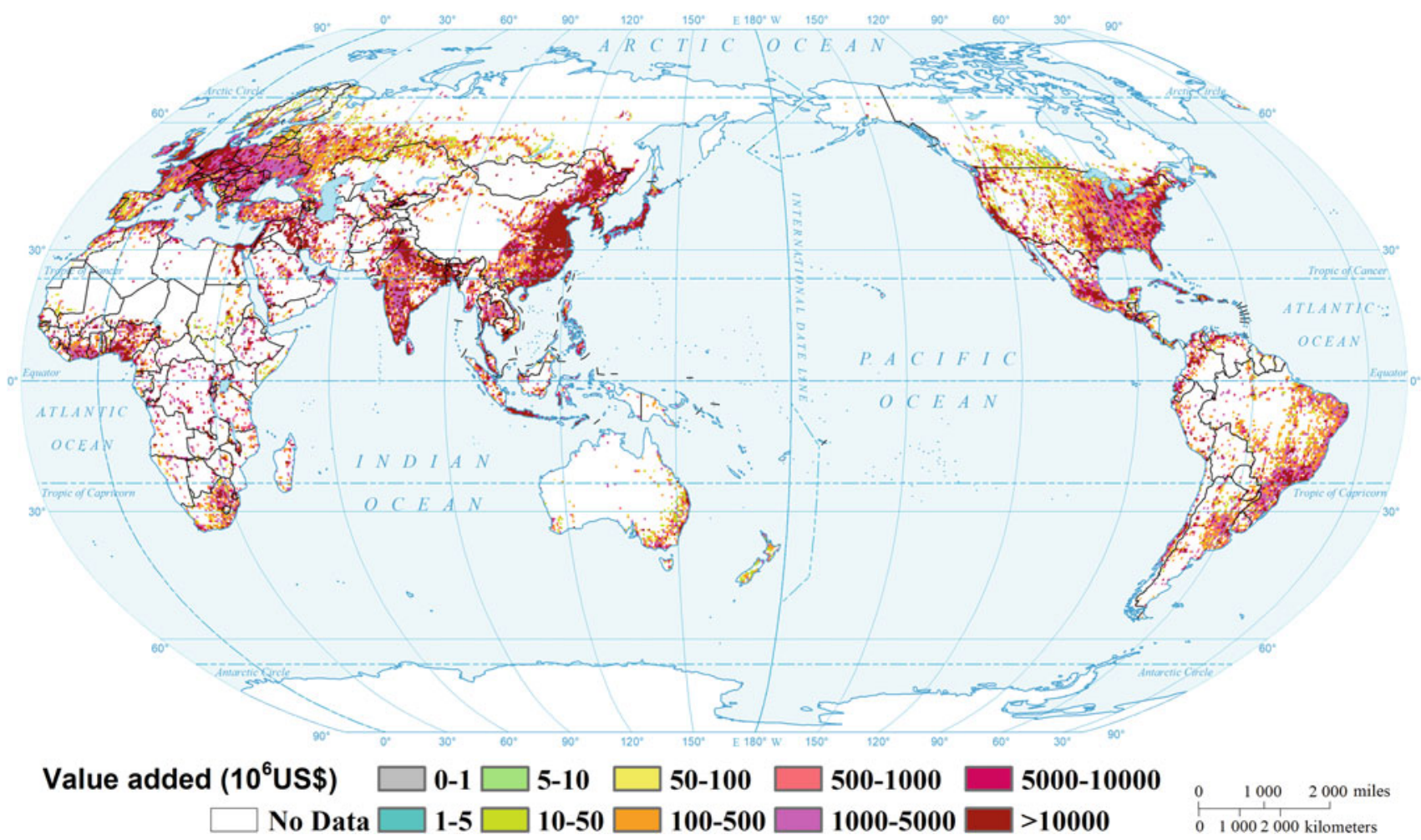




\section{Projected global industrial value added (2050, SSP2)}

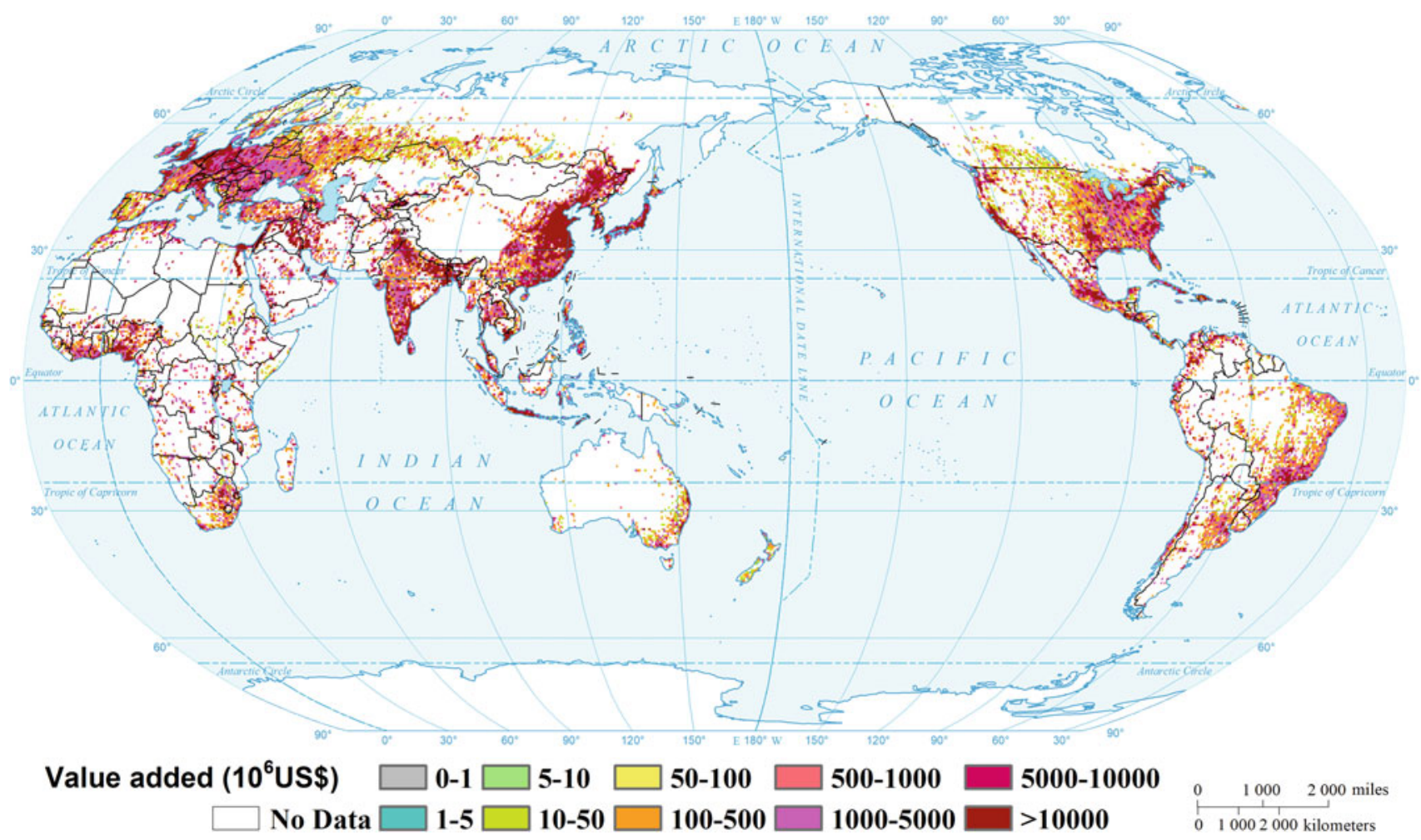

Projected global industrial value added (2050, SSP3)

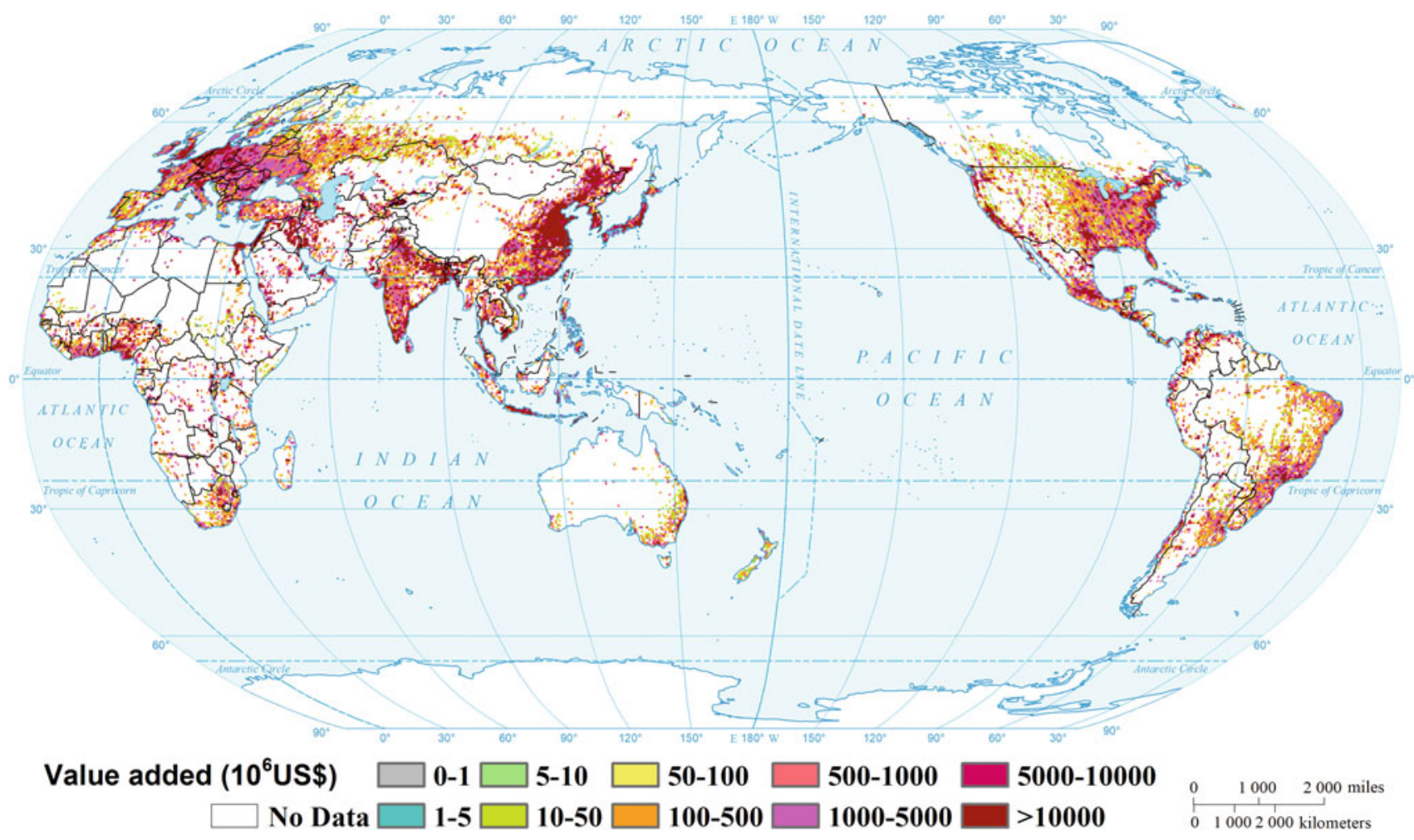




\section{References}

Dong, L., H. Liang, Z. Gao, and X. Luo. 2016. J. Ren. Spatial Distribution of China's Renewable Energy Industry: Regional Features and Implications for a Harmonious Development Future. Renewable and Sustainable Energy Reviews 58: 1521-1531.

Jamal, J.A., H. Marco, K. Wolfgang, and D. Ali. 2013. Integration of logistic regression, Markov chain and cellular automata models to simulate urban expansion. International Journal of Applied Earth Observation and Geoinformation 21: 265-275.

Li, L., J. Li, Z. Jiang, L. Zhao, and P. Zhao. 2018. Methods of population spatialization based on the classification information of buildings from China's first national geoinformation survey in urban area: A case study of Wuchang District, Wuhan City China. Sensors 18 (8): 2558.

Tobler, W.R. 1979. Smooth pycnophylactic interpolation for geographical regions. Journal of the American Statistical Association 74 (367): 519-530.
Wang, L., S. Wang, Y. Zhou, W. Liu, Y. Hou, J. Zhu, and F. Wang. 2018. Mapping population density in China between 1990 and 2010 using remote sensing. Remote Sensing of Environment 210: 269281.

Xue, Q., and W. Song. 2020. Spatial distribution of China's industrial output values under global warming scenarios RCP4.5 and RCP8.5. ISPRS International Journal of Geo-Information 9(12): 724.

Xue, Q., W. Song, and H. Zhu. 2018. Global industrial added value 1 $\mathrm{km}$ square grid dataset. Journal of Global Change Data \& Discovery 2 (1): 9-17.

Zhao, M., W. Cheng, C. Zhou, M. Li, N. Wang, and Q. Liu. 2017. GDP spatialization and economic differences in South China based on NPP-VIIRS nighttime light imagery. Remote Sensing 9 (7): 673.

Zhuo, L., X. Zhang, J. Zheng, H. Tao, and Y. Guo. 2015. An EVI-based method to reduce saturation of DMSP/OLS nighttime light data. Acta Geographica Sinica 70 (8): 1339-1350.
Open Access This chapter is licensed under the terms of the Creative Commons Attribution 4.0 International License (http:// creativecommons.org/licenses/by/4.0/), which permits use, sharing, adaptation, distribution and reproduction in any medium or format, as long as you give appropriate credit to the original author(s) and the source, provide a link to the Creative Commons license and indicate if changes were made.
The images or other third party material in this chapter are included in the chapter's Creative Commons license, unless indicated otherwise in a credit line to the material. If material is not included in the chapter's Creative Commons license and your intended use is not permitted by statutory regulation or exceeds the permitted use, you will need to obtain permission directly from the copyright holder. 